\title{
O espaço público construído das cidades brasileiras: o ativismo projetual do planejamento urbano versus ocupação
}

\section{The built public space of Brazilian cities: projectual activism of urban planning versus occupation}

Dayse Luckwü Martins - Doutora em Desenvolvimento Urbano pela Universidade Federal de Pernambuco (UFPE). Professora da Universidade Federal de Pernambuco (UFPE). E-mail: dayse.luckwu@ufpe.br

Lúcia Leitão Santos - Doutora em Arquitetura pela Universidade do Porto (FAUP). Professora da Universidade Federal de Pernambuco (UFPE). E-mail: leitaolu@gmail.com

\section{Resumo}

Observa-se nos últimos anos um movimento de retorno ao espaço público construído das cidades. Esse movimento, sob a ótica do planejamento urbano, respalda o que chamamos nesta pesquisa de ativismo projetual, em contraponto a movimentos espontâneos de ocupação daqueles espaços. Portanto, o presente artigo objetiva investigar se o que denominamos de ativismo projetual tem definido as intervenções que vêm sendo propostas para esses espaços em particular. Para tanto, trabalha-se com a hipótese de que ações projetuais, quando advindas desse ativismo, contribuem para tornar o espaço público edificado objeto-mercadoria dentro do sistema capitalista. Tendo como referência teórica a noção de dispositivos técnicos e disposições sociais, argumenta-se, ao final, que o ativismo projetual coloca em debate a lógica do planejamento urbano, seu caráter homogeneizante, midiático e privatista em detrimento da condição do espaço enquanto lugar do encontro e do debate.

\section{Palavras-chave}

Espaço público construído. Ativismo projetual. Movimento de retorno. Dispositivos construídos. Disposições sociais.

\begin{abstract}
It is observed that, in contemporaneity, it has been occurred a return movement to the built public space of cities. From the perspective of urban planning, this movement corroborates what is called, in this research, by projectual activism, in contrast to spontaneous movements of occupation of those spaces. Therefore, this article aims to investigate whether what we call projectual activism has defined the interventions that have been proposed for these particular spaces. Thus, the article works with the hypothesis that projectual actions, when arising from this activism, contribute to making the built public space into an object-commodity within the capitalist system. Having as theoretical reference the notion of technical devices and social dispositions, it is argued in the end that projectual activism debates the logic of urban planning, its homogenizing, mediatic and privatizer character in opposition to the space's condition as a place of meeting and debate.
\end{abstract}

\section{Keywords}

Built public space. Projectual activism. Return movement. Built device. Social dispositions. 


\section{REFLEXÕES INICIAIS SOBRE A CONDIÇÃO DO ESPAÇO PÚBLICO CONSTRUIIDO DAS CIDADES}

O notável destaque dado ao espaço público no meio acadêmico, bem como nas discussões acerca do planejamento urbano, é o ponto de partida para refletirmos sobre um movimento de retorno ao espaço público construído das cidades $^{1}$. Movimento este que, sob a ótica do planejamento urbano, respalda o que neste artigo denominaremos de ativismo projetual para designar as ações mediante as quais o projeto urbanístico assume um papel de protagonismo criando marcas do lugar que têm como foco o espaço público construído.

O objetivo central deste texto é fazer uma discussão a respeito da lógica privada ou privativista, em contraponto a movimentos espontâneos de ocupação ou de resistência à ordem estabelecida nesses espaços. Partimos da hipótese de que o ativismo projetual tem pautado as intervenções nos espaços públicos construídos de cidades brasileiras de modo nem sempre adequado. Com essa discussão, esperamos contribuir para a reflexão sobre como as intervenções contemporâneas nos espaços públicos construídos são alvo de ações que os tornam objetos-mercadoria dentro do sistema capitalista. Nesse contexto, o artigo ora apresentado tem um caráter teórico-reflexivo e se propõe a lançar um olhar sobre a realidade brasileira de forma ampla, sem a delimitação de um recorte espacial específico.

Uma primeira constatação diz respeito a uma crescente preocupação acerca dos espaços públicos das cidades e como esses espaços têm sido incorporados a um discurso atrelado à reativação da urbanidade ${ }^{2}$ dentro do planejamento urbano, como nos confirma Delgado (2011, p. 15): “[...] aumenta su consideración en tanto que elemento inmanente de toda morfología urbana y como destino de todo tipo de intervenciones urbanizadoras, en el doble sentido de objeto de urbanismo y de urbanidade".

A Academia se mostra atenta a tal panorama. Diversas áreas do saber, como Arquitetura e Urbanismo, Sociologia, Geografia, Direito, Ciências Políticas, têm procurado debater a importância do tema, abrindo caminho para

\footnotetext{
Neste artigo, tratamos do espaço público das cidades, que diz respeito aos espaços urbanos de uso livre público, como praças, parques, ruas, jardins públicos, que se distinguem de espaços semipúblicos e privados e são alvo de ações por parte dos atores citadinos. Enfatizamos o termo construído junto à expressão espaço público para diferenciar de outras esferas ou dimensões que o espaço público contempla.

2 O Dictionnaire de l'urbanisme et de l'aménagement, de Choay e Merlin (1988), traz o seguinte conceito para urbanidade: "du latin urbanitas (la vie à Rome, puis, par extension, qualité morale de ce qui appartient à la ville, enfin bon ton, politesse)" (CHOAY; MERLIN, 1988, p. 868). Sobre urbanidade, ver também Le Goff (1988).
} 
novas abordagens e análises, traçando possibilidades de tangenciamentos e convergências entre si.

Passando a ocupar um dos lugares centrais dentro do planejamento e do projeto urbano na atualidade, também encontramos o debate em torno do espaço público em textos publicados em colunas de jornais ou sites não especializados ${ }^{3}$. Esses textos registram uma retomada do espaço público por parte da população em várias partes do mundo. Movimentos reivindicatórios e de ocupação ${ }^{4}$ acenam para a importância desses espaços nas cidades. Como afirma Harvey: “[...] os movimentos pelo direito à cidade (apesar da diversidade e de sua orientação) encontram-se em plena atividade em dezenas de cidades de todo o mundo" (HARVEY, 2014, p. 15). Outras vezes, as notícias se dão em face de ações oriundas do investimento por parte do planejamento urbano que favorecem a transformação dos espaços públicos construídos se alinhando à crescente privatização dos espaços urbanos frente à política neoliberal imposta pelo sistema capitalista, no qual a cidade é tida como mercadoria (VAINER, 2002).

A crescente valorização do espaço público, seja sob aspectos teóricos conceituais, seja projetualmente, tem se dado não só no cenário nacional como também internacional. Carrión (2004) confirma essa percepção ao destacar que:

el espacio público ha adquirido um significativo peso en los debates sobre la ciudad y en la agenda de las políticas urbanas; lo cual no es casual que así ocurra, porque se ha convertido en uno de los temas de mayor confrontación social respecto de la ciudad (CARRIÓN, 2004, p. 55).

Carrión (2004) observa ainda que a confrontação com o tema se dá em meio a um cenário de crise urbana, devido a uma privatização crescente do espaço público e à perda da função social que este desempenha nas cidades. Assim, se por um lado a agenda do planejamento urbano contemporâneo tem trazido à tona a questão do espaço público, muitas vezes para legitimar um discurso de inclusão e coesão social a partir de projetos urbanísticos ${ }^{5}$ (TRIGUEIRO, 2012), por outro lado se observa o contraponto (Figura 1), a partir de movimentos de ocupação espontâneos que, em alguns casos, tomam os espaços públicos das cidades com pautas reivindicatórias, promovendo o embate direto com o planejamento urbano estabelecido (HARVEY, 2014).

3 Ver Folha de S. Paulo, Estadão, Carta Capital, Le Monde, para citar alguns, que têm publicado matérias abordando a temática do espaço público fora dos círculos acadêmicos.

4 Sobre os movimentos sociais, ver Harvey (2014), na obra Cidades rebeldes. Citamos ainda uma publicação da editora Boitempo, uma coletânea sobre os movimentos de rua no Brasil de julho de 2013, intitulada Cidades rebeldes: passe livre e as manifestacões que tomaram as ruas do Brasil (2013).

5 Ver artigo "Pacificação da cidade: a urbanidade legitimada", de Trigueiro (2012). 
Figura 1 - Foto de pichação de autor desconhecido em portão no centro histórico de João Pessoa/PB

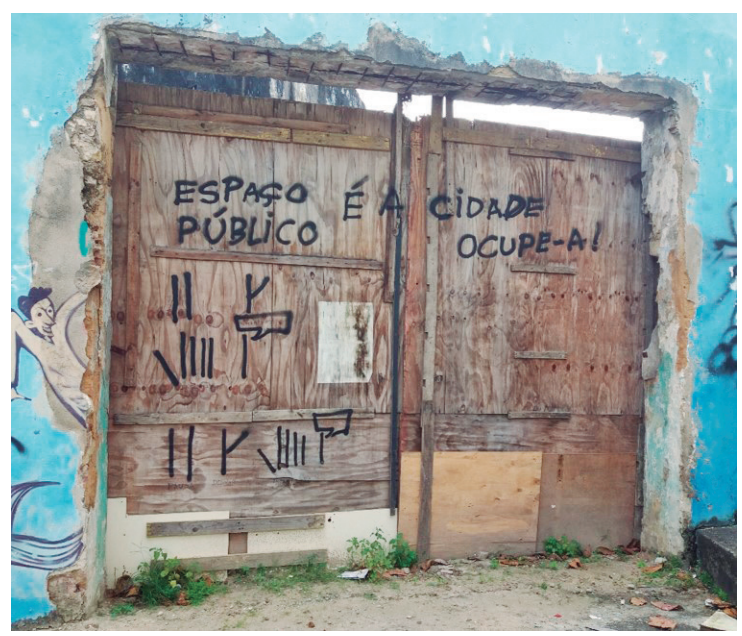

Fonte: Dayse Martins, out. 2017.

Evidenciam-se assim, nesse cenário, outros atores que reivindicam seu lugar no espaço público das cidades enquanto direito a elas nos termos lefebvrianos. Cabe-nos questionar: quem seriam esses atores? O que querem ou representam? Por que o espaço público das cidades, enquanto temática, tem chamado tanta atenção quando diversos autores (CARRIÓN, 2004; DELGADO, 2011; LEFEBVRE, 2008) consideram que a cidade vive uma crise há muito já debatida?

A crise urbana tem sido discutida sob diferentes facetas e contextos temporais, e, nesse sentido, podemos trazer à tona alguns autores e momentos específicos para abordá-la e situá-la.

Sob a ótica de Lefebvre (2008), a crise urbana tem como marco o processo de industrialização da sociedade. A decorrência da crise da cidade industrial, palco do estabelecimento do capitalismo, é o ponto de partida dos processos que modificaram a cidade enquanto objeto e impuseram, enquanto fenômeno, "a problemática urbana, à escala mundial” (LEFEBVRE, 2008, p. 24). A visão do autor situava esse processo como um momento de ruptura entre campo e cidade cujas consequências se configuraram como uma verdadeira revolução para a história das cidades. O pensamento lefebvriano repousava sobre o entendimento da cidade como o objeto definido, enquanto o urbano era algo virtual, configuravase como processo que abarcava a "sociedade urbana" (LEFEBVRE, 2008, p. 26). A pertinência do autor para debater a crise urbana reside na discussão das questões conceituais - não só para aquele momento, mas como contributo à 
contemporaneidade - decorrentes dos processos de urbanização que o sistema capitalista impôs à sociedade. Processos estes excludentes e expropriatórios, que negam o direito à cidade em sentido mais amplo.

Embora Lefebvre discuta a crise da cidade retomando o momento da Revolução Industrial, o autor, como se sabe, escreveu sua obra na década de 1960, imerso, portanto, em uma crise urbana de outra ordem: a crise do projeto de cidade sob a égide do Movimento Moderno. Essa década se apresentou como um outro momento temporal marcante para a temática da crise urbana, assinalada pelos movimentos sociais que tomaram as ruas de cidades nos Estados Unidos e na Europa, contrapondo-se ao modelo de planejamento urbano baseado nos princípios do Movimento Moderno.

A "morte da rua", como a literatura sobre o assunto passou a tratar as grandes escalas dos projetos urbanísticos modernistas, assim como o protagonismo urbanístico atribuído ao automóvel, foi um dos “jargões” presentes nos manifestos daquele período. Uma das grandes questões emergentes a partir de então foi a de que o urbanismo modernista mudou a escala de abordagem do fazer a cidade. A escala humana não era mais uma referência essencial ao processo de urbanização. A escala passou a ser a da produção, como resposta ao processo desencadeado pela Revolução Industrial que, dois séculos antes, havia sido iniciado. Essa mudança de enfoque recai diretamente sobre a produção física do espaço público das cidades. Cabe apontar aqui que a crise urbana se expressa como decorrência das transformações do capital, que delineariam, na década seguinte, anos 1970, a crise do capitalismo estabelecida de forma mais nítida e desencadeariam o início do processo neoliberalizante que se apresentaria nas cidades a partir da crescente privatização enquanto projeto de cidade.

Sob a ótica urbanística, é importante destacar que os problemas do planejamento urbano modernista se apresentavam distintos para as diferentes realidades da Europa e dos Estados Unidos. Ressalte-se que naquele momento as críticas se davam sobre a percepção acerca da realidade urbana, não se pautando ainda sobre dados de base empírica que pudessem mensurar a realidade percebida.

No Brasil, a década de 1960 também assinalou o marco de um momento de crise urbana, ainda que de outra ordem, uma vez que o Movimento Moderno aqui representou uma linguagem de renovação da Arquitetura nacional. A crise urbana no Brasil recaía de fato sobre questões de ordem infraestrutural das cidades, como o recrudescimento da questão da moradia, os reflexos de um acelerado processo migratório do campo para as cidades e a falta de infraestrutura destas (MARICATO, 1987), além de efeitos políticos decorrentes do início da ditadura militar e do consequente tolhimento da liberdade individual dos cidadãos. 
O contraponto foi que esse período também foi marcado pelo Movimento de Reforma Urbana, cuja pauta reivindicatória trazia como questões o direito à cidade e à cidadania, a função social da cidade e a sua gestão democrática (FERNANDES, 2010).

Passados cinquenta anos, a crise urbana vivenciada no Brasil se mostra com maior gravidade. Ratificada por um projeto neoliberalista, a crise do capital passa a ser legitimadora da esfera privada e se apresenta de maneira ainda mais excludente em um país de capitalismo periférico. As questões atuais recaem sobre a mesma falta de infraestrutura urbana, a fragilidade institucional que acaba por privilegiar o privado em detrimento do público, os problemas relativos à mobilidade urbana, à insegurança nos espaços públicos, à moradia, à segregação socioespacial, para citar alguns.

Desse modo, ao focarmos o debate para falar da crise sob a ótica urbana, tal debate recai diretamente sobre a temática do espaço público das cidades. Arantes (2000) observa que o espaço público passou a permear o ideário de arquitetos e urbanistas a partir das críticas advindas dos anos 1960. Segundo a autora:

No intuito de devolver a cidade moderna à coletividade expropriada ao longo do processo de constituição das grandes aglomerações urbanas contemporâneas, arquitetos e urbanistas entregaram-se, particularmente a partir de meados dos anos 1960, a uma verdadeira obsessão pelo lugar público, em princípio o antídoto mais indicado para a patologia da cidade funcional (ARANTES, 2000, p. 98).

Nesse sentido, uma suspeita inicial, no panorama geral, recai sobre o fato de que o retorno ao espaço público se deu em função de uma ausência de projeto de cidade que a Pós-modernidade e a contemporaneidade não conseguiram responder adequadamente. Harvey (1992), de certa forma, corrobora com essa percepção ao fazer a seguinte observação:

No campo da arquitetura e do projeto urbano, considero o Pósmodernismo no sentido amplo como uma ruptura com a ideia modernista de que o planejamento e o desenvolvimento devem concentrar-se em planos urbanos de larga escala, de alcance metropolitano, tecnologicamente racionais e eficientes, sustentados por uma arquitetura absolutamente despojada (as superfícies "funcionalistas" austeras do Modernismo de estilo internacional"). O Pós-modernismo cultiva, em vez disso, um conceito de tecido urbano como algo necessariamente fragmentado, um "palimpsesto" de formas passadas superpostas umas às outras e uma "colagem" de usos correntes, muitos dos quais podem ser efêmeros (HARVEY, 1992, p. 69). 
Embora, no Pós-modernismo, tenha sido esboçada por alguns a ideia de um new urbanism, surgido nos Estados Unidos nas últimas décadas do século passado, esse movimento não chegou a se tornar um ideário intelectual e político em comparação com o Movimento Moderno, que se pautava sobre uma produção fordista dos espaços urbanos. Sobre o momento seguinte, o Pós-modernismo nas cidades, Harvey (1992, p. 96) aponta que "[...] ficção, fragmentação, colagem e ecletismo, todos infundidos de um sentido de efemeridade e caos, são, talvez, os temas que dominam as atuais práticas da arquitetura e do projeto urbano". Essa assertiva do autor sobre o projeto urbano se coaduna com o projeto do espaço público das cidades a partir daquele período para países centrais do capitalismo. Foi, portanto, nesse cenário que o espaço público passou a ser o foco das atenções, como uma resposta à crise da cidade que o Movimento Moderno e o Pós-modernismo não conseguiram responder.

Com efeito, a despeito de uma crise urbana inconteste, principalmente se observamos o caso brasileiro, país de capitalismo periférico cuja crise é de ordem infraestrutural, o que assistimos nos dias atuais é um movimento manifesto de retorno ao espaço público construído das cidades. Movimento este que possui duas principais vertentes: uma por parte do planejamento urbano e outra por parte dos atores sociais, como Harvey (2014) discute em Cidades rebeldes. Poderíamos falar, diante desse cenário, de um retorno ao espaço público das cidades como uma possibilidade de contraponto à crise urbana? Essa questão abre o diálogo com problemas concretos que nortearam a construção das reflexões aqui propostas.

Dentro desse contexto de crise urbana, o espaço público aparece como uma temática transversal, ou seja, como algo que percorre os debates sobre a cidade a partir do Pós-modernismo e na contemporaneidade, exatamente porque esse é o lugar onde os processos de coexistência tomam forma, como debatem Joseph (1988), Carrión (2004) e Delgado (2011). Retoma-se, assim, aquilo que Carrión (2004), no texto já citado, apontou: a ideia de que o espaço público participa do embate ao caráter privatizador da cidade que o mercado busca impor dentro do sistema capitalista de cunho neoliberalizante, apresentando-se como o lugar do civismo, do encontro e da visibilidade (JOSEPH, 1999). No caso do Brasil, o espaço público construído passou a se constituir, portanto, como o contraponto a uma cidade cada vez mais privatizada.

No entanto, se o espaço público desponta como uma temática que põe em debate os processos de coexistência social e o lugar dos conflitos, Delgado (2011) observa que o outro lado da moeda seria a maneira como, no sistema capitalista, o espaço público passa a ser objeto de uma estratégia de pacificação e negação dos dissensos. Portanto, para esse autor, o espaço público contemporâneo acaba 
por adquirir uma acepção política mais forte enquanto instrumento da ação governamental. Delgado destaca esse ponto ao afirmar:

La noción de espacio público, en tanto que concreción física en que se dramatiza la ilusión ciudadanita, funcionaría como un mecanismo a través del cual la clase dominante consigue que no aparezcan como evidentes las contradicciones que la sostienen, al tiempo que obtiene también la aprobación de la clase dominada al valerse de un instrumento - el sistema político - capaz de convencer a los dominados de su neutralidad. Consiste igualmente en generar el espejismo de que se ha producido por fin la deseada unidad entre sociedad y Estado, en la medida en que los supuestos representantes de la primera han logrado un consenso superador de las diferencias de clase (DELGADO, 2011, p. 24).

Nos meios acadêmicos, o debate se volta para a questão da espetacularização dos espaços públicos, sua homogeneização, seu esvaziamento e a consequente perda da urbanidade. Os espaços são projetados segundo uma lógica programática que favoreça a coesão social no discurso dos fabricantes, como aponta Trigueiro (2012). Sob a ótica do planejamento urbano, os fabricantes seriam os técnicos e aqueles ligados à gestão pública, cuja prerrogativa é a elaboração dos projetos para os espaços públicos.

Utilizando uma linguagem lefebvriana (LEFEBVRE, 2000), o espaço concebido seria o que designa o espaço dos fabricantes. O espaço vivido seria o dos outros atores sociais, os usuários do espaço, aqueles que o vivenciam. Sob a ótica certeauniana, o espaço dos fabricantes seria o das estratégias, cuja força é a manipulação do lugar. O espaço vivido seria o praticado, lugar das táticas dos usuários comuns. Assim, enquanto a estratégia define um próprio, ou seja, um lugar de poder, a tática joga com o tempo, com as astúcias que o momento permite (DE CERTEAU, 1994, p. 46). Sob essa perspectiva, os movimentos de ocupação, de resistência à ordem estabelecida, contam com as táticas de apropriação que o momento possibilita.

No atual cenário, o espaço público contemporâneo se encontra imerso em uma crise a partir do momento em que passou a ser produzido com um caráter homogeneizante e midiático, ou seja, voltado para o espetáculo, deixando, assim, de ser uma autêntica representação da diversidade socioespacial. Para Jacques (2009), o processo de homogeneização nega os conflitos próprios do espaço público, se tomarmos uma concepção mais filosófica do termo. Para a autora:

Os atuais projetos urbanos contemporâneos são realizados no mundo inteiro segundo uma mesma estratégia: homogeneizadora, espetacular e consensual. Estes projetos buscam transformar os espaços públicos em cenários, espaços desencarnados, fachadas sem corpo: pura imagem publicitária (JACQUES, 2009, não paginado). 
A autora corrobora o que Delgado (2011) aponta sobre os espaços públicos atuais quando esses também passam a ser concebidos segundo uma lógica de produção, intrínseca ao capitalismo, que visa a criação de marcas a partir de cenários destinados à competitividade das cidades (VAINER, 2002). O espaço público passou a ser, assim, objeto-mercadoria sob a ótica do capital e, para o planejamento urbano, moeda de troca e apaziguamento, principalmente para as áreas menos favorecidas das cidades.

\section{CONTRAPONTO OU ATIVISMO PROJETUAL?}

O contraponto às questões postas acima vem de vários autores que têm se dedicado a mostrar alternativas ao uso dos espaços públicos nas cidades, apontando para soluções técnicas projetuais que favoreçam o encontro a partir da multiplicidade de usos, relacionando-os, assim, à ativação e à animação da vida urbana.

Na década de 1960, os autores já citados tratavam a questão da rua e do espaço público construído das cidades por meio de uma percepção de caráter mais subjetivo e dedutivo, a exemplo das observações de Jacobs (2007) acerca da multiplicidade de usos e das fachadas ativas que criavam o que a autora chamava de "os olhos da rua". Atualmente, observa-se a busca por mensurar parâmetros empíricos que venham a comprovar como soluções projetuais atuam para favorecer a dinamização do espaço público construído. As análises recaem sobre as relações entre a forma da edificação e a forma urbana, tendo aí o espaço público como protagonista. São exploradas as relações entre morfologia urbana, gabarito, recuos, densidade construtiva, tipologia das edificações com outros fatores como mobilidade, graus de incomodidade e segurança urbana.

Nesse sentido, Jan Gehl (2013) tem se destacado na atualidade ao refletir sobre como os espaços públicos edificados nas cidades devem ser pensados e projetados voltados para a escala das pessoas. De certo modo, o autor estabelece a continuidade da crítica surgida nos anos 1960 acerca da maneira como a forma dos espaços da cidade pode servir como um fator atrativo ou repulsivo para a permanência das pessoas nos espaços públicos. Se Jacobs (2007), na década de 1960, cunhou a expressão "os olhos da rua", designando um ato de vigilância de caráter social, Gehl (2013, p. 39-41) utiliza o conceito de "cidade ao nível dos olhos", abordando uma escala projetual para analisar o projeto do espaço urbano a partir do plano de visão que o olho humano é capaz de abarcar.

Ainda que sigam enfoques que se distinguem, tais autores alertam para questões de visibilidade, contato social e escala. Gehl (2013) chama a atenção 
para a perda da dimensão humana, algo que os projetos urbanísticos, a partir do Movimento Moderno, não conseguiram incorporar. A escala da cidade passou a ser, em grande parte, a escala do automóvel, com as implicações decorrentes de tal fator. Assim, os contatos interpessoais no espaço público se tornaram mais escassos, e este, consequentemente, tornou-se mais inseguro.

Ao defender que a escala humana passou a ser negligenciada pelos planejadores urbanos a partir do Modernismo, o autor argumenta ainda sobre a ênfase do planejamento urbano de caráter mais pragmático, em função, principalmente, da resolução da questão do tráfego. A solução proposta, segundo Gehl (2013), dá-se com a diminuição dos automóveis nas ruas em prol do aumento do pedestrianismo. Tal atitude se reporta ao desenho urbano, com soluções projetuais para vias compartilhadas, e também à gestão pública, com a proibição de tráfego de veículos em determinadas áreas da cidade.

Após as constatações acerca das falhas do planejamento urbano e de como não se deve projetar as cidades, Gehl (2013, p. 6-7) defende quatro princípios norteadores para o planejamento, sendo eles: a) cidades cheias de vida, b) cidades saudáveis, c) cidades seguras e d) cidades sustentáveis. Tais pontos acabam por fornecer um "manual" aos planejadores urbanos, principalmente no que tange ao projeto dos espaços públicos das cidades.

Embora esses estudos tenham dado uma enorme contribuição para repensar a animação da vida urbana, principalmente do cotidiano urbano, alguns aspectos precisam ser destacados. O primeiro deles é o fato apontado por Saboya, Moraes Netto e Vargas (2015) quanto à falta, muitas vezes, de comprovação científica de tais estudos, ou seja, baseiam-se em apreensões e se tornam verdades válidas enquanto suposição sem os dados empíricos que os comprovem.

Um segundo aspecto a se destacar é o fato de que o planejamento urbano acaba por importar modelos de realidades, contextos e sociedades distintas, tomados como exemplos práticos e exitosos em determinados contextos, não se aplicando em realidades muito diferentes. Isso vem a reforçar, de certa maneira, o caráter homogeneizador, indesejado, dado ao espaço público das cidades na contemporaneidade, como já apontado. Segundo Saboya, Moraes Netto e Vargas (2015):

É possível também que as conclusões sejam válidas para um contexto específico, mas não para outros, o que é especialmente problemático se considerarmos que esses autores clássicos raramente circunscrevem suas conclusões a contextos específicos, deixando implícito que seriam válidas para todos os lugares (SABOYA, MORAES NETTO; VARGAS, 2015, não paginado). 
Alguns desses estudos e publicações se prestam, portanto, como "manuais" destinados aos planejadores urbanos. Muitas vezes, esses "manuais" são escritos sobre cidades cujos problemas estão muito distantes da realidade de extrema segregação socioespacial, em se tratando do cenário brasileiro. Assim, o que percebemos é uma "importação" de modelos transportados para a realidade de nossas cidades.

O terceiro ponto a se observar é a preponderância dada nesses estudos ao objeto construído, o que passamos a denominar de dispositivos técnicos ${ }^{6}$, como um reativador das disposições sociais ${ }^{7}$. O espaço público passa a ser guiado por uma lógica voltada para o projeto, atribuindo-se aos primeiros, os dispositivos técnicos, a prerrogativa de mobilização da vida urbana. Observamos também que os dispositivos construídos desempenham o papel de importantes atores dentro da lógica projetual do espaço público contemporâneo. Nesse aspecto, o que Akrich (2014, p. 161) diz faz todo o sentido: “[...] os objetos técnicos possuem um conteúdo político no sentido de que eles constituem os elementos ativos de organização das relações dos homens entre eles e com seu ambiente”.

Ou seja, aos objetos técnicos, entendidos aqui como os dispositivos construídos, atribui-se uma ação política no espaço, como aponta a autora. Desta forma, os dispositivos se apresentam como atores fundamentais dentro da lógica do ativismo projetual corroborando, como apontado inicialmente, com o fato de que o projetourbanístico (e o arquitetônico) passou a agir como protagonista das intervenções nos espaços públicos construídos, criando marcas do lugar. Muitas vezes, esse é o único elo entre os fabricantes e os usuários, uma vez que o espaço público passou a ser, agora, o lugar da visibilidade daqueles que o projetam dentro do raciocínio da lógica do mercado.

Os fabricantes dos espaços públicos nesse cenário passam a agir segundo estratégias (DE CERTEAU, 1994) de intervenção sobre os espaços públicos utilizando-se do ativismo projetual, ou seja, são guiados pela lógica norteada pelo projeto do espaço. Dessa maneira, os fabricantes se revestem de um discurso que se volta para essa prática, o que pode vir a contribuir para a criação de espaços públicos cenográficos e para o caráter homogeneizador do espaço. Observase que essa dinâmica serve ao projeto do espaço público segundo a ótica dos fabricantes dentro do planejamento urbano, referendando o que pressupõe a dialética do sistema capitalista como temos assinalado.

Por dispositivo técnico, entende-se os objetos construídos que equipam o espaço (JOSEPH, 1999).

Por disposição social, entende-se as formas ou maneiras de arranjos sociais em interação com os dispositivos técnicos (JOSEPH, 1999). 


\section{O CENÁRIO DA PRODUÇão DO ESPAÇO PÚBLICO DAS CIDADES NO BRASIL}

No Brasil, temos observado que as intervenções se evidenciam não como um planejamento urbano de caráter mais amplo, mas como marcas de gestões municipais, muitas vezes a partir da transposição de modelos de realidades distintas, a exemplo das imagens que seguem.

Figura 2 - Rio de Janeiro-RJ (1), João Pessoa-PB (2), Penedo-AL (3), Recife-PE (4)
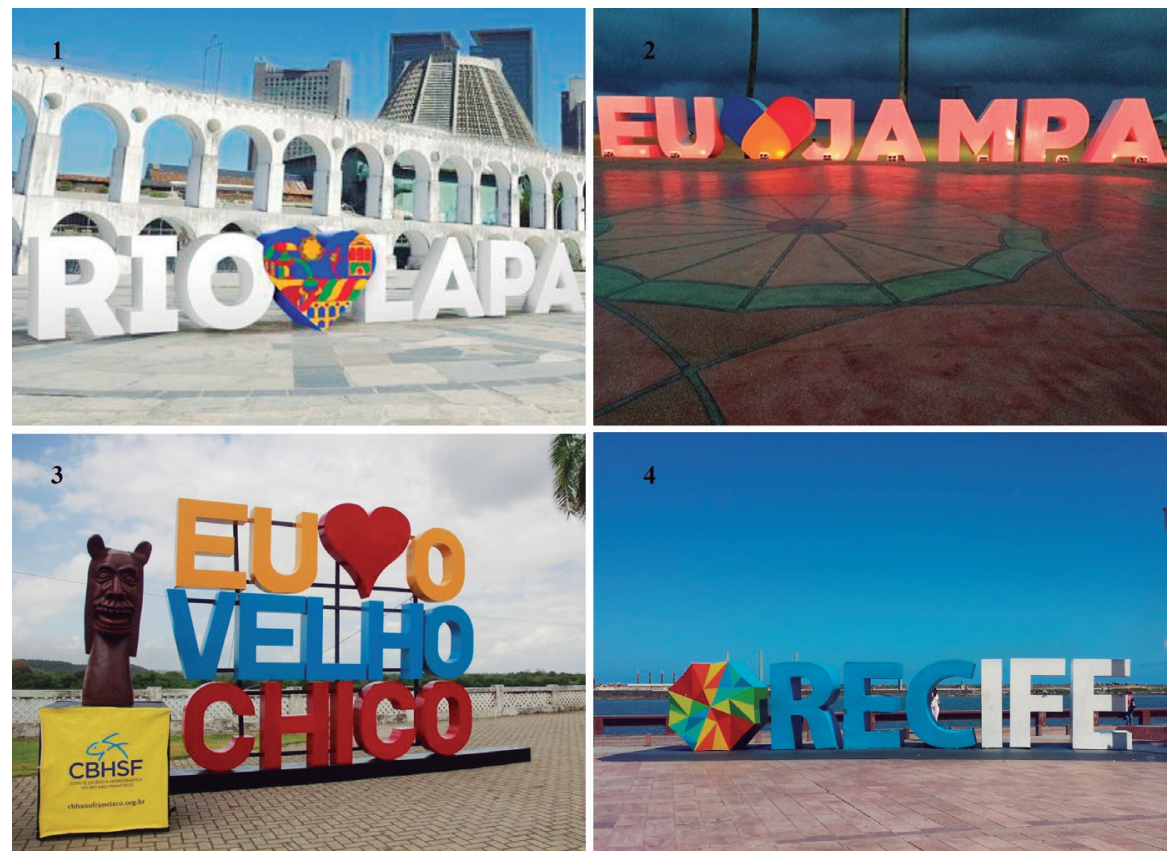

Fontes: Férias Brasil (s. d.) (1), Prefeitura... (2015) (2), Totem... (2017) (3) e Marco Zero... (2016) (4).

Para os fabricantes, o discurso sobre os espaços públicos seria, nesse caso, uma legitimação de que se está operando transformações urbanas, ou seja, que estão trabalhando sobre e para a cidade em última instância. Fica evidenciado que os dispositivos espaciais, nesse contexto, passam a ser atores principais dentro dessa lógica vivenciada na contemporaneidade, desempenhando um papel político no cenário do espaço público construído do País visando atrair classes sociais que possam pagar por esses espaços, colocando em segundo plano, na maioria das vezes, disposições sociais indesejáveis a esses espaços. Dessa maneira, vemos questões cada vez mais complexas que passam a encaminhar as discussões sobre os espaços públicos na realidade brasileira. 
Figura 3 - Praça Mauá Rio de Janeiro

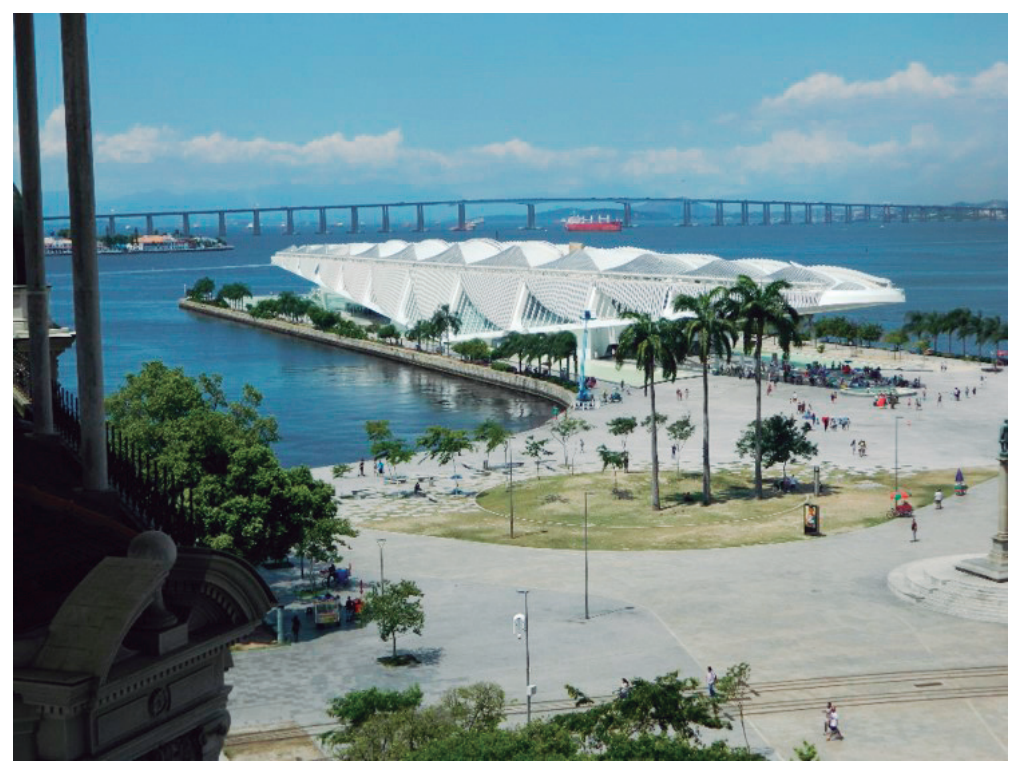

Fonte: Dayse Martins, jan. 2019.

Um dado relevante sobre os espaços públicos das cidades no Brasil diz respeito à sua produção norteada por questões políticas. Em primeiro lugar, por parte das gestões municipais que se utilizam do ativismo projetual para deixar assinalada a sua própria marca. Destaca-se, nesse contexto, uma prática política brasileira cujo efeito é a descontinuidade das ações, a exemplo de espaços públicos que passaram por processos de qualificação ou intervenções urbanísticas em outra gestão ou durante a gestão de algum partido opositor e, por isso, são alvos do descaso da gestão em vigor, passando a carecer de manutenção de seus espaços.

Em segundo lugar, observa-se a existência de associações conflituosas entre o poder público e o mercado imobiliário, não raro com prejuízos para a produção dos espaços públicos da cidade, a exemplo da produção e reprodução de espaços cada vez mais segregados e da consequente perda de vitalidade urbana e da urbanidade. Circunstância que reflete a condição de fragilidade do espaço público no cenário brasileiro, muitas vezes objeto de troca entre o público e o privado.

Evidencia-se a carência de espaços públicos de lazer qualificados, principalmente nas áreas mais periféricas das cidades para as populações menos favorecidas. Muitas vezes as reivindicações da população versam sobre a implantação de equipamentos e mobiliário urbano. $\mathrm{O}$ atendimento a essas reivindicações são alvo igualmente de ações políticas de caráter midiático e geram espaços homogeneizados com pouca qualidade espacial. 
Figuras 4 - Mobiliário urbano em praças visto em várias cidades do país

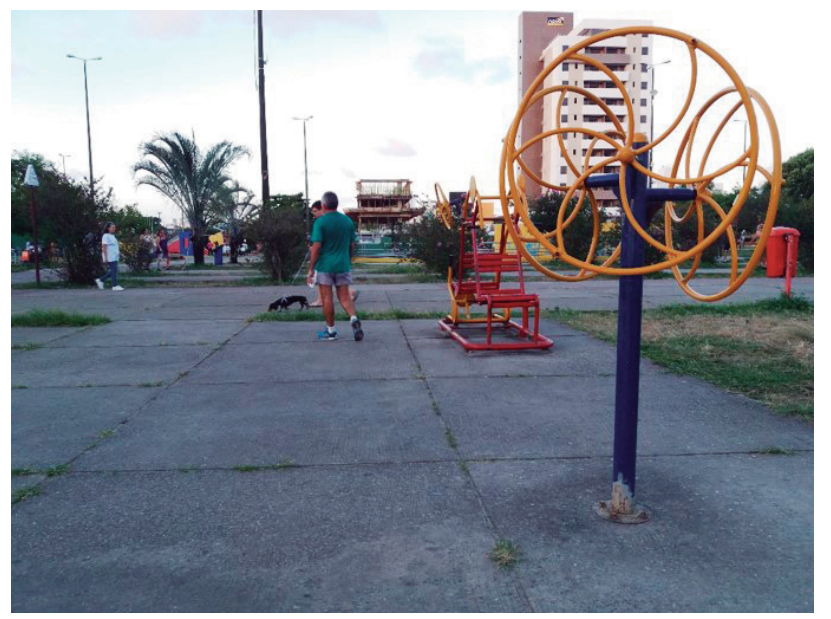

Fonte: Dayse Martins, out. 2017.

Em terceiro lugar, parte da população encara a intervenção em determinados espaços urbanos sob uma ótica político-partidária. Observamos, nesse sentido, que a ação da população se mostra pontual, isto é, não há, muitas vezes, um questionamento sobre o tipo de espaço público que está sendo construído em sua articulação com outras políticas sociais, de mobilidade urbana, saúde e educação. Articulação esta fundamental para colocar o espaço público em primeiro plano como o lugar das diferenças para o planejamento urbano. Já para as classes sociais que se fecham nos espaços privados não lhes interessa o espaço público socialmente construído. Em todos os aspectos apontados, o espaço público das cidades enquanto lugar da possibilidade do encontro, do dissenso e da contradição se esvazia.

Outras questões emergem sobre as necessidades e carências dos espaços públicos das cidades brasileiras, o que as coloca, sob diversos aspectos, em condições de extrema desvantagem em relação às cidades que oferecem um espaço público construído qualitativamente diferenciado. Uma dessas questões versa sobre a tecnologia como um fator de ressignificação e apropriação dos espaços. Esse debate parece ainda muito distante da grande maioria das cidades brasileiras, uma vez que a carência por espaços mais qualificados ainda é tão grande que as tecnologias ligadas aos espaços públicos se resumem, não raro, aos grandes centros, em uma pequena proporção. $\mathrm{E}$ muitas vezes, quando estão disponíveis, estão atreladas a dispositivos de segurança, reportando-nos à violência urbana, um problema grave em se tratando das cidades no Brasil. Tornam-se necessários, cada vez mais, aparatos de segurança nos espaços 
públicos construídos, que precisam ser vigiados para que atos de violência ou "incivilidade" não aconteçam, prezando-se, assim, pelo "bom" uso do espaço. Contudo, observa-se que a vigilância se dá, de maneira mais ostensiva, em grande parte, sobre os "espaços-marca" para a cidade, inserindo-se o espaço público, dessa forma, dentro da lógica do espetáculo, como discutido anteriormente.

Figura 5 - Ronda policial (1) e vigilante (2) do Parque Solón de Lucena - João Pessoa-PB

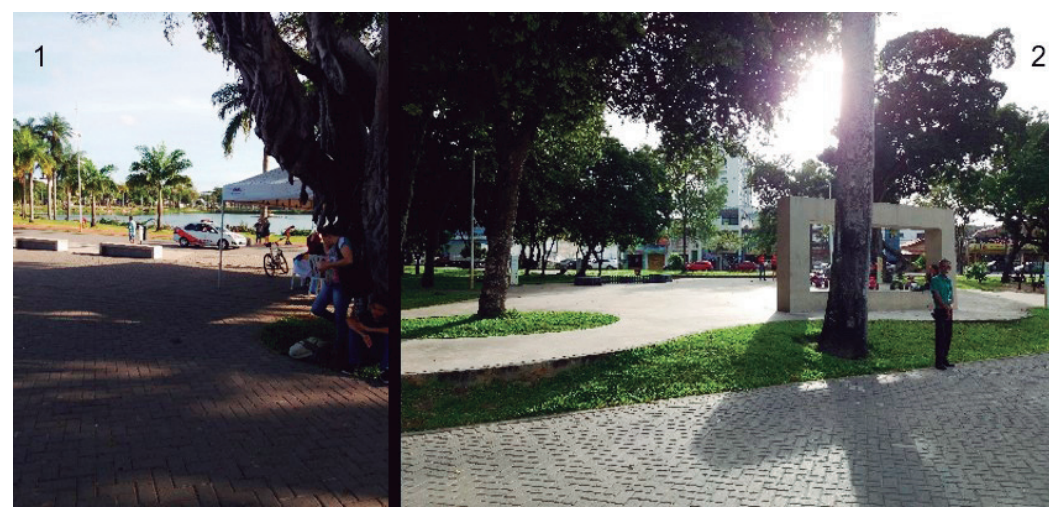

Fonte: Dayse Martins, out. 2017.

Destarte, embora busquemos ser otimistas e encontremos alguns avanços sobre a questão dos espaços públicos construídos das cidades no Brasil; principalmente no que diz respeito a processos de ocupação e apropriação espontâneos ou organizados, podemos destacar um quadro de vulnerabilidades sob a ótica do planejamento urbano. Percebemos que estamos muito longe de um processo focado nos espaços públicos enquanto base de um planejamento que considere o seu caráter mais democrático. O planejamento assim pensado deveria, na verdade, estar direcionado ao público usuário dos espaços públicos urbanos, nos desafios de como aplicar possibilidades de metodologias que observem as reais necessidades da população local e como essas demandas se articulam com outras políticas públicas (JOSEPH, 2004) que contemplem a qualidade e a possibilidade do encontro das diferenças.

\section{CONSIDERAÇÕES FINAIS}

Ao fazermos algumas considerações finais, reportamo-nos ao fato de que o caráter principal do espaço público é aquele em que os estranhos vão se encontrar, como apontam diversos autores. Portanto, diante de um quadro cada 
vez mais excludente, fomentado por um sistema econômico que se alimenta da segregação para sua própria sustentação, vivemos, no País, uma falácia quando se observa de perto a proposição dos espaços públicos de nossas cidades. O que vemos não é a construção do espaço público como lugar do encontro na urbe, e sim um ativismo projetual por parte dos fabricantes representantes do planejamento urbano "oficial", da produção de ruas, praças, parques, jardins, como a ideia de que se está pensando a cidade.

Assim sendo, dentro do cenário descortinado, percebemos que os dispositivos construídos do espaço, seguindo a lógica projetual dos fabricantes, passaram a desempenhar um papel tão importante para a produção física do espaço que se apresentam como um "ator principal", destacado em primeiro plano, a partir do momento em que o projeto para o espaço público ganhou o protagonismo como estratégia, reportando-nos a De Certeau (1994), dentro do discurso dos fabricantes, aqui representado pelas ações do planejamento urbano no sistema capitalista.

Nesse contexto, não surpreende que os projetos para os espaços públicos construídos reforcem o caráter homogeneizador se observados em diversos ambientes urbanisticamente propostos, a exemplo do que ocorre no estabelecimento do programa de necessidades e dos dispositivos espaciais, bem como do mobiliário urbano. Esse aspecto faz com que os projetos para os espaços públicos incorporem a lógica de modelos globalizantes, cuja expressão, muitas vezes, é a criação de marcas midiáticas.

É dessa maneira que, em resposta ao objetivo de contribuir com reflexões sobre como os espaços públicos construídos das cidades, em específico as brasileiras, cujas ações são alvo de projetos que os tornam objetos-mercadoria dentro de um sistema capitalista, é possível perceber como o ativismo projetual se reveste de determinadas práticas dentro do planejamento urbano, como temos apontado.

Pesquisas sobre movimentos de ocupação, a exemplo dos "Ocupe", evidenciam que há, sim, um movimento manifesto de retorno aos espaços públicos das cidades por parte de uma grande parcela da população. Nesse sentido, é possível considerar que há um duplo movimento de retomada desses espaços que se faz não só por parte dos fabricantes, mas também por parte dos atores sociais a partir de um desejo latente de ocupá-los. Resta a estes, os usuários, "táticas", expressão feliz de De Certeau (1994), de utilização, ocupação e resistência, que acabam por transformar os dispositivos a partir da ação e, ao fazê-lo, também passam a conceber uma nova relação espacial com os espaços, apontando para as reais possibilidades que as relações espaciais e sociais podem favorecer para os espaços públicos das cidades. 
Observamos a vontade de ocupar os espaços públicos urbanos, mas, muitas vezes, há a carência desses espaços ou de qualificação e oferta de espaço público para a população. Em determinados casos, a falta de cuidados por parte das gestões municipais não favorece o seu uso e sua ocupação. Portanto, é possível falar de um movimento de retorno latente que depende de muitos fatores.

Em decorrência do que foi tratado até aqui, destacamos a importância que a temática dos espaços públicos construídos das cidades passou a assumir na atualidade. Esses se tornam de extrema importância para estratégias de resistência e respostas ao processo de mercantilização das cidades. Ressaltamos a pertinência de investigarmos por que se dá o que passamos a designar como movimento de retorno ao espaço público dada a importância e abrangência do tema. Particularmente, buscamos observar o espaço público construído nas cidades brasileiras na contemporaneidade em face de toda a problemática de crise urbana já apresentada.

Assim, ao concluirmos, alertamos que os espaços públicos urbanos não podem ser silenciados a partir de práticas que os tornem homogêneos e os pacifiquem. O espaço público contemporâneo das cidades nunca precisou tanto ser o espaço de outras vozes, lugar das diferenças que propicia o encontro, o contato e o diálogo, como também o lugar do embate e dos conflitos que revestem o espaço público do seu caráter mais democrático.

\section{REFERÊNCIAS}

AKRICH, M. Como descrever os objetos técnicos? Boletim Campineiro de Geografia, Campinas, v. 4, n. 1, p. 161-182, 2014.

ARANTES, O. B. F. O lugar da arquitetura depois dos modernos. São Paulo: EDUSP, 2000.

BERQUE, A. Paisagem-marca, paisagem-matriz: elementos da problemática para uma geografia cultural. In: CORRÊEA, R. L.; ROSENDAHL, Z. (org.). Paisagem, tempo e cultura. Rio de Janeiro: EdUERJ, 1998. p. 84-91.

BORJA, J.; MUXI, Z. El espacio público, ciudad y ciudadanía. Barcelona: [s. n.], 2000.

CARRIÓN, F. Espacio público: punto de partida para la alteridade. FLACSO Andes, Bogotá, 2004. Disponível em: https:/ /www.flacsoandes.edu.ec/sites/ default/files/agora/files/1228415744.espacio_publico._punto_de_partida_ para_la_alteridad_2.pdf. Acesso em: 16 maio 2017. 
CHOAY, F; MERLIN, P. Dictionnaire de lúrbanisme et de lámenagement. Paris: Presses Universitaires de France, 1988.

DE CERTEAU, M. A invenção do cotidiano: artes de fazer. Petrópolis: Vozes, 1994.

DELGADO, M. E1 espacio público como ideología. Madrid: Los libros de la Catarata, 2011.

FÉRIAS BRASIL. Centro e Lapa. Férias Brasil, [s. l.], [s. d.]. Disponível em: https://m.feriasbrasil.com.br/rj/riodejaneiro/centroelapa.cfm. Acesso em: 11 dez. 2021.

FERNANDES, E. O Estatuto da Cidade e a ordem jurídico-urbanística. In: CARVALHO, C.; ROSSBACH, A. C. (org.). O Estatuto da Cidade comentado. São Paulo: Ministério das Cidades/ Aliança das Cidades, 2010. p. 55-70.

GEHL, J. Cidades para pessoas. São Paulo: Perspectiva, 2013.

HARVEY, D. Condição pós-moderna: uma pesquisa sobre as origens da mudança cultural. São Paulo: Edições Loyola, 1992.

HARVEY, D. O enigma do capital: e as crises do capitalismo. São Paulo: Boitempo, 2011.

HARVEY, D. Cidades rebeldes: do direito à cidade à revolução urbana. São Paulo: Martins Fontes, 2014.

JACOBS, J. Morte e vida de grandes cidades. São Paulo, Martins Fontes, 2007.

JACQUES, P. B. Notas sobre espaço público e imagens da cidade. Arquitextos, São Paulo, ano 10, jul. 2009. Disponível em: http://www.vitruvius.com.br/ revistas/read/arquitextos/10.110/41. Acesso em: 17 abr. 2020.

JOSEPH, I. El transeunte y el espacio urbano. Buenos Aires: Gedisa, 1988.

JOSEPH, I. L'espace public comme lieu de l'action. Les Annales de la Recherche Urbaine, Paris, n. 57-58, p. 211-217, 1992.

JOSEPH, I. Paisagens urbanas, coisas públicas. Caderno CRH, Salvador, n. 30/31, p. 11-40, jan./ dez. 1999.

LE GOFF, J. Por amor às cidades: conversações com Jean Lebrun. São Paulo: Editora da Unesp, 1998.

LEFEBVRE, H. A revolução urbana. Belo Horizonte: Ed. UFMG, 1999. 
LEFEBVRE, H. Espaço e política. Belo Horizonte: Editora UFMG, 2008.

LEFEBVRE, H. La production de l'espace. Paris: Éditions Anthropos, 2000. LEFEBVRE, H. O direito à cidade. São Paulo: Centauro, 2001.

LEITÃO, L.; LACERDA, N. O espaço na geografia e o espaço da arquitetura: reflexões epistemológicas. Cadernos Metrópole, São Paulo, v. 18, n. 37, p. 803 $822,2016$.

MACEDO, A. C. A carta do novo urbanismo norte-americano. Arquitextos, São Paulo, ano 7, mar. 2007. Disponível em: http://www.vitruvius.com.br/ revistas/read/arquitextos/07.082/262 Acesso em: 14 jun. 2017.

MARCO ZERO de Recife. Uma senhora viagem, [s. l.], 20 mar. 2016. Disponível em: https://www.umasenhoraviagem.com/2016/03/marco-zerode-recife.html. Acesso em: 11 dez. 2021.

MARICATO, E. Política habitacional no regime militar. Petrópolis: Vozes, 1987.

MARICATO, E. et al. Cidades rebeldes: Passe Livre e as manifestações que tomaram as ruas do Brasil. São Paulo: Boitempo: Carta Maior, 2013.

MARTINS, D. L. Narrativas sobre a materialidade do espaço público na cidade brasileira contemporânea: o caso da cidade de João Pessoa. 2018. Tese (Doutorado em Desenvolvimento Urbano) - Programa de Pós-Graduação em Desenvolvimento Urbano, Universidade Federal de Pernambuco, Recife, 2018. PREFEITURA de João Pessoa inaugura novo letreiro no calçadão da orla. G1 PB, João Pessoa, 28 dez. 2015. Disponível em: http://g1.globo.com/pb/ paraiba/noticia/2015/12/prefeitura-de-joao-pessoa-inaugura-novo-letreiro-nocalcadao-da-orla.html. Acesso em: 11 dez. 2021.

SABOYA, R. T.; MORAES NETTTO, V.; VARGAS, J. C. Fatores morfológicos da vitalidade urbana: uma investigação sobre o tipo arquitetônico e seus efeitos. Arquitextos, São Paulo, ano 15, maio 2015. Disponível em: http:/ /www.vitruvius. com.br/revistas/read/arquitextos/15.180/5554. Acesso em: 28 mar. 2017.

SILVA, T. Conhecido bairro boêmio do Rio, Lapa inaugura na Praça dos Arcos sua nova atração. Agência Brasil, Brasília, DF, 10 jan. 2019. Disponível em: https://agenciabrasil.ebc.com.br/geral/noticia/2019-01/lapa-inauguramobiliario-urbano-na-praca-dos-arcos. Acesso em: 03 dez. 2021. 
TOTEM "Eu amo o Velho Chico" é sucesso na orla de Penedo. F5 Alagoas, Maceió, 12 nov. 2017. Cultura. Disponível em: http:/ f5alagoas.com. $\mathrm{br} /$ editoria/cultura/totem-eu-amo-o-velho-chico-e-sucesso-na-orla-depenedo/40/24239. Acesso em: 11 dez. 2021.

TRIGUEIRO, M. Pacificação da cidade: a urbanidade legitimada: o caso dos espaços públicos do grand ensemble Les Minguettes, em Lyon. In: HOLANDA, F. et al. (org.). Urbanidades. Rio de Janeiro: Folio Digital/ Letra e Imagem, 2012. p. 81-113.

VAINER, C. B. Pátria, empresa e mercadoria. Notas sobre a estratégia discursiva do Planejamento Estratégico Urbano. In: ARANTES, O.; VAINER C. B.; MARICATO, E. A cidade do pensamento único: desmanchando consensos. Petrópolis: Vozes, 2002. p.75-103. 